\title{
PRODUÇÃO CIENTÍFICA DE MAPAS CONCEITUAIS EM EDUCAÇÃO: UM ESTUDO BIBLIOMÉTRICO
}

\section{CONCEPTUAL MAPS SCIENTIFIC PRODUCTION IN EDUCATION: A BIBLIOMETRIC STUDY}

\author{
Paula Magda da Silva Roma ${ }^{1}$ \\ Carolina Magda da Silva Roma ${ }^{2}$
}

\begin{abstract}
Resumo: Este trabalho investiga o perfil da produção científica de mapas conceituais em educação, por meio do estudo bibliomético através da base de dados Scopus. Os resultados evidenciaram uma crescente produção científica, desde a publicação do primeiro artigo, em 1982, até março de 2020, totalizando 784 publicações. Essa produção foi ranqueada entre 54 países, sendo que o Brasil ocupa a sétima posição, com 60 artigos. No cenário nacional, o autor Paulo Miranda Rogério Correia, da Universidade de São Paulo, está na lista entre os dez autores que mais publicaram sobre o tema. Os dez artigos mais citados traziam aplicação da técnica com diferentes objetivos educacionais, a saber: como instrumento de aprendizagem, visando à organização, apresentação e revisão do conhecimento, como recurso de colaboração e ferramenta de avaliação.
\end{abstract}

Palavras-chave: Mapas conceituais; Educação; Estudo bibliométrico.

\begin{abstract}
This work investigates the profile of concept maps scientific production in education through a bibliometric study using the Scopus database. The results showed an increasing scientific production from the first paper, in 1982, until March 2020, totaling 784 articles. These publications were ranked among 54 countries, with Brazil occupying the seventh position, with 60 articles. In the national scenario, Paulo Miranda Rogério Correia, from the University of São Paulo, is one of the ten most published authors on the topic. The ten most cited papers showed the technique application had different educational objectives: as a learning tool, aiming at the organization, the presentation and the review of knowledge, as a collaboration resource, and assessment tool.
\end{abstract}

Keywords: Concept maps; Education; Bibliometric study.

\section{Introdução}

As Tecnologias Educacionais (TE) desempenham um papel relevante na aquisição de competências e habilidades, gerando novas formas de interação entre os campos da educação e da comunicação, através da contextualização dos conteúdos, do confronto das informações obtidas por diferentes tecnologias e da criação da própria TE pelo trabalho conjunto de docentes e discentes, transformando-os de consumidores em produtores (BRASIL, 2004).

\footnotetext{
1 Doutora em Física, UFMG. IFSULDEMINAS, Três Corações, Minas Gerais, Brasil. E-mail: paula.roma@ifsuldeminas.edu.br

${ }^{2}$ Doutora em Administração, UFMG. FURG, Rio Grande, Rio Grande do Sul, Brasil. E-mail: carolina.roma@furg.br
} 
Nesse contexto, os Mapas Conceituais (MCs) constituem uma tecnologia educacional que promove a aprendizagem significativa por meio da organização e associação de conceitos conectados por termos de ligação de forma hierarquizada (NOVAK; CAÑAS, 2010). Moreira (2013) define o conceito de aprendizagem significativa como a incorporação de novos conhecimentos à estrutura cognitiva com significado e compreensão, promovendo a capacidade de explicação, transferência, descrição e de enfrentamento de situações novas.

Apresentados na década de 1970, por Joseph Novak, os MCs têm sido amplamente empregados para organizar e compartilhar o conhecimento nos âmbitos educacional e corporativo (CORREIA, 2012; NOVAK; CAÑAS, 2010). No contexto educacional, os MCs têm sido utilizados para avaliação da aprendizagem em sala de aula (CORREIA; SILVA; ROMANO; 2010), como instrumento para identificar conexões disciplinares (CORREIA et al., 2014), como ferramenta de compartilhamento de conhecimento e informação, estimulando processos colaborativos (CORREIA et al., 2016), e como recurso que viabiliza o hábito da pesquisa (MOUSINHO, 2019). Além disso, podem ser empregados como uma ferramenta metacognitiva no processo de aprendizagem (TAVARES; MÜLLER; FERNANDES, 2008).

Embora os MCs constituam tecnologias educacionais relevantes no processo de ensino-aprendizagem, trabalhos científicos que acompanham a evolução das pesquisas sobre o uso dessas ferramentas no contexto educacional ainda são incipientes. Para suprir essa lacuna na literatura, realizamos um mapeamento quantitativo sobre $o$ desenvolvimento desses estudos. Para isso, utilizamos a base de dados Scopus, empregando os termos-chave "concept maps" (mapas conceituais) e "education" (educação) e, em seguida, procedemos com a análise quantitativa através dos pacotes Bibliometrix e biblioshiny. Por meio dessa metodologia, esta pesquisa buscou responder as seguintes questões: (i) Qual o volume de publicação relacionada ao uso de MCs no contexto educacional ao longo dos anos?; (ii) Qual o perfil dos periódicos que publicam tais trabalhos?; (iii) Quais os autores mais produtivos com relação ao tema?; (iv) Quais os autores mais citados?

Os principais resultados indicaram uma crescente produção científica entre 1982 até março de 2020. A consulta à base de dados resultou em 784 publicações, das quais 60 foram elaboradas por autores afiliados a instituições brasileiras. Essa produção científica está distribuída entre 54 países, totalizando 26 áreas de conhecimento, que apresentaram como palavras-chave mais frequentes os seguintes termos e expressões: "aprendizagem 
significativa", "educação científica", "pensamento crítico", "avaliação" e "ensino superior”. No Brasil, a Universidade de São Paulo (USP) e o pesquisador Paulo Rogério Miranda Correia, afiliado a essa instituição, apresentaram-se como a instituição e autor de maiores destaques da produção brasileira na área. Os dez artigos mais citados evidenciaram as potencialidades do mapeamento conceitual em diversos contextos educacionais.

Essa pesquisa oferece como contribuição direta para o campo da educação um mapeamento nacional e internacional da produção científica sobre o tema. Além disso, espera-se despertar no leitor e, principalmente, no professor, o interesse em empregar essa tecnologia no processo de ensino e aprendizagem.

\section{Mapas conceituais: princípios metodoógicos e teóricos}

Os MCs são organizadores gráficos que auxiliam na organização e representação do conhecimento por meio de uma rede de conceitos e proposições interligadas hierarquicamente (NOVAK; CAÑAS, 2010). A unidade de uma proposição é formada pelo conjunto: conceito inicial $\rightarrow$ termo de ligação $\rightarrow$ conceito final. A seta indica o sentido da leitura da proposição, enquanto o termo de ligação conecta explicitamente os dois conceitos. O termo de ligação deve conferir maior clareza semântica à proposição e, para isso, é necessário que se empregue um verbo devidamente flexionado (CORREIA et al., 2016). Por exemplo, a expressão "Luz onda eletromagnética" não exprime informações claras devido à ausência de um termo que conecte os conceitos inicial "luz" e final "onda eletromagnética". A inclusão da expressão "é um exemplo de", como termo de ligação, permite que a frase seja reelaborada para: "Luz é um exemplo de onda eletromagnética". Quando há clareza semântica, o leitor é capaz de avaliar se a proposição está correta do ponto de vista conceitual. Assim, um dos maiores desafios do mapeador é encontrar o menor número de palavras que expresse de forma genuína aquilo que se deseja representar.

A Figura 1 representa um MC sobre a tecnologia de mapeamento conceitual. Observa-se que a relação entre os conceitos segue uma estrutura hierarquizada, mediada por termos de ligação. Os conceitos mais gerais iniciam o mapa e são progressivamente detalhados, sendo essa a principal diferença entre os mapas conceituais e outros organizadores gráficos, como fluxogramas e mapas mentais (MOREIRA, 2010). 
Figura 1: Mapa conceitual sobre a tecnologia de mapeamento conceitual

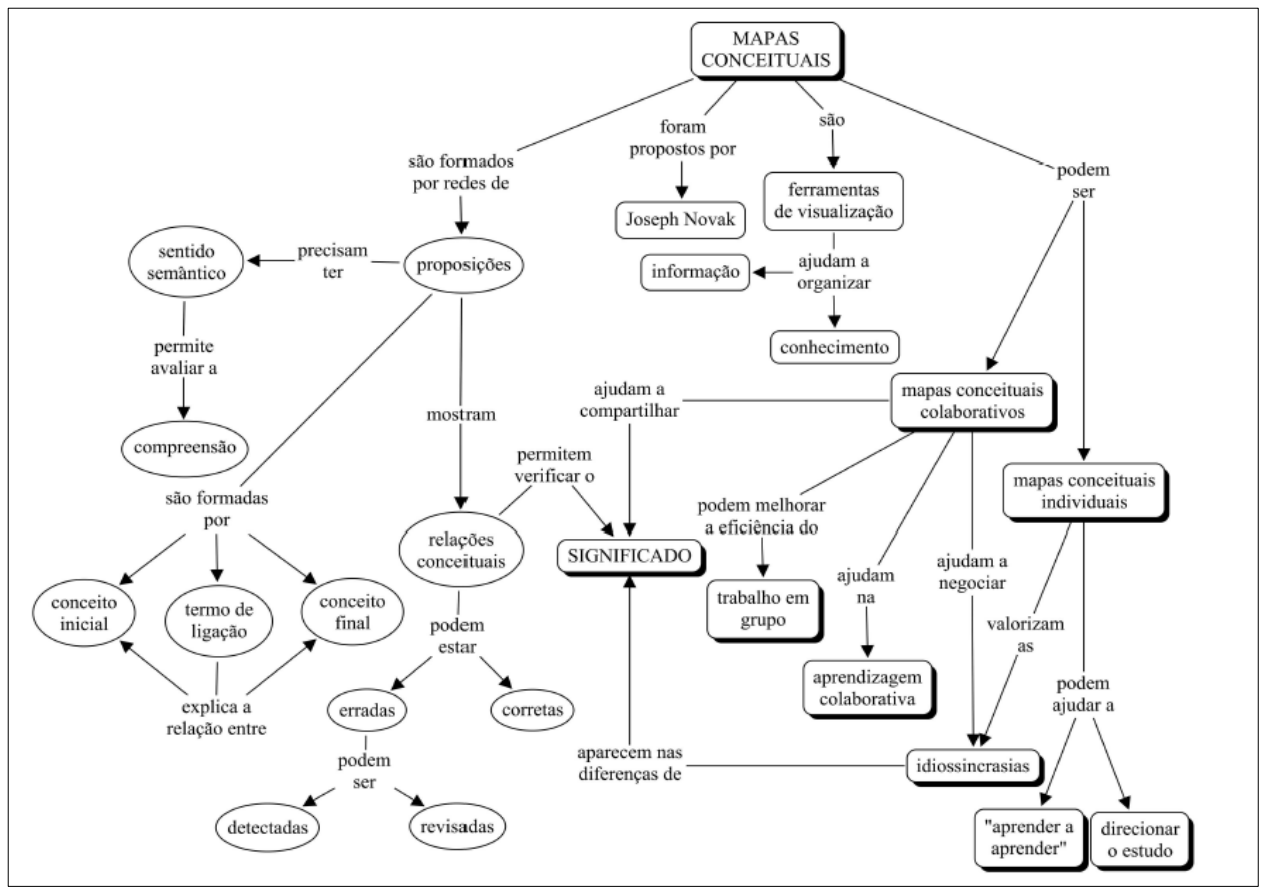

Fonte: Correia, Silva e Romano (2010, p. 4402-3).

Por meio das Tecnologias da Informação e Comunicação, é possível gerar MCs interativos e colaborativos que auxiliam na aprendizagem significativa. O programa Cmaptools $^{3}$ (CAÑAS et al., 2004), distribuído gratuitamente pelo Institute for Human and Machine Cognition (IHMC), é um exemplo disso. O software possibilita mover os conceitos juntamente com o termo de ligação, bem como o conjunto de conceitos e seus termos para reestruturar o mapa. A ferramenta ainda permite a inserção de links nas caixas dos conceitos, como arquivos de vídeos, áudios, textos e anotações manuscritas digitalizadas, além de links para conteúdos on-line para auxiliar na construção do mapa. Com o uso da internet, os mapas podem ser elaborados colaborativamente de forma assíncrona ou síncrona (NOVAK; CAÑAS, 2010).

A fundamentação teórica dos MCs tem aporte na Teoria da Aprendizagem Significativa, proposta por Ausubel (2000), que tem como princípio os processos cognitivos humanos. De acordo com essa teoria, a aprendizagem significativa ocorre quando uma nova informação se ancora em conceitos relevantes, significativos e existentes na estrutura cognitiva do aprendiz. Esse processo de ancoragem representa uma ampliação e uma reconfiguração da estrutura mental do indivíduo, permitindo que este desenvolva relações e acesse novos conhecimentos. Por exemplo, se os conceitos de "força" e "campo", provenientes da Física, já fizerem parte da estrutura cognitiva do

\footnotetext{
${ }^{3}$ Disponível para download em: http://cmap.ihmc.us. Acesso em: 05 mar. 2021.
} 
aluno, será mais fácil para o estudante ancorar novas informações (como os conceitos de "força elétrica e "campo elétrico") a essas noções pré-existentes (AUSUBEL, 2000; MOREIRA, 1999).

Para Ausubel (2000), duas condições são necessárias para que ocorra a aprendizagem significativa e ambas se relacinam ao conhecimento prévio do aprendiz: (i) o material a ser aprendido deve ser relacionável de forma lógica e não arbitrária ao conhecimento prévio do individuo, o que implica que o aluno apresente em sua estrutura cognitiva conhecimentos relevantes com os quais esse material possa se relacionar; e (ii) que o aluno apresente predisposição para aprender. Com relação a esta última condição, Novak e Cañas (2010) propõem o uso de estratégias de ensino e de avaliação que tenham como princípio os conhecimentos prévios do aluno.

Em contraste com a aprendizagem significativa, Ausubel (2000) apresenta o conceito de aprendizagem mecânica, definida como aquela com pouca ou quase nenhuma relação com as informações pré-existentes na estrutura cognitiva do indivíduo, de forma literal. A aquisição de um novo conteúdo sem sentido ou a memorização de fórmulas e conceitos representa uma aprendizagem mecanizada com baixa retenção de conhecimento. $\mathrm{O}$ autor descreve a aprendizagem, de um modo geral, como um processo que relaciona continuamente as modalidades significativa e mecânica.

Para Moreira (2013), a atividade realizada em sala de aula situa-se entre esses dois conceitos. Caso o ensino promova a aprendizagem significativa e o aluno apresente interesse em aprender, este poderá progredir na direção da aprendizagem significativa. No extremo oposto, se o ensino for comportamentalista, prioriznando o treinamento de respostas corretas, a aquisição de conceitos estará voltada para a aprendizagem mecânica.

Nesse cenário, os MCs promovem um conhecimento significativo e uma ampliação no entendimento de conceitos, pois há flexibilidade ao se negociar significados (CUNHA; DE PAULA; SUANNO, 2015). Essa negociação não consiste apenas nos conceitos aprendidos através de estudos, incluindo também o elemento pessoal, pois cada pessoa externaliza de forma única a hierarquia dos conceitos já internalizados, relacionando-os com o que foi apresentado por uma teoria, por uma pessoa ou por outros conceitos.

Novak, Cañas (2010) apontam que o uso da técnica de mapeamento também favorece a aprendizagem significativa porque os MCs auxiliam na organização e na estruturação do conhecimento, ainda que essa estruturação precise ser construída, peça 
por peça, por meio de conceitos e proposições interligadas. Além disso, a técnica permite uma retenção do conhecimento por mais tempo.

\section{Procedimentos metodológicos}

Este artigo utilizou a pesquisa bibliométrica como abordagem metodológica. Conforme Araújo (2006), a bibliometria é uma técnica quantitativa e estatística que surgiu no início do século, em virtude da necessidade do estudo e da avaliação da produção e comunicação científica. Segundo o autor, esse tipo de análise desenvolveu-se inicialmente a partir de leis empíricas sobre a produtividade dos autores em termos da produção científica (Lei Lotka), a frequência de palavras em um texto (Lei de Zipf) e a produtividade de periódicos (Lei de Bradford).

Complementarmente, a bibliometria é uma ferramenta que possibilita caracterizar o estado da ciência e da tecnologia através da produção científica global, em um determinado nível de especialização (OKUBO, 1997). Essa metodologia permite que se evidencie a produção científica de um país em relação ao mundo, de uma instituição em relação a um país e de cientistas em relação aos seus pares. Nesse sentido, a bibliometria representa uma análise quantitativa da produção científica, sendo explicitada, por exemplo, pelos seguintes indicadores: volume de artigos publicados por ano, por autores, países, instituições, rede de colaboração, perfil dos periódicos que mais publicaram na área, frequência de autoria e palavras-chave, dentre outros.

Neste estudo, utilizamos a base de dados Scopus, acessível via web por subscrição institucional, na qual foram submetidas as palavras-chave "concept maps" e "education". De acordo com os filtros aplicados à consulta, buscamos os artigos que continham em seus títulos, resumos e palavras-chave os termos de interesse, fixando-se o período de busca até março de 2020. Os dados bibliográficos recuperados foram exportados no formato bibtex e a análise bibliométrica foi realizada através dos pacotes bibliometrix e biblioshiny, através do software R (ARIA; CUCCURULLO, 2017).

O bibliometrix é uma ferramenta com várias rotinas para importar dados bibliográficos das bases de dados Scopus, Web of Science, Pubmed e Cochrane, perfazendo a análise bibliométrica e construindo matrizes de dados para cocitação, acoplamento, análise de colaboração científica e análise conjunta por meio de comandos feitos no próprio R. O biblioshiny permite ao usuário realizar essas análises através de 
uma interface web interativa, sendo mais recomendado para quem apresenta poucas habilidades com a linguagem de programação.

\section{Resultados e Discussões}

A consulta à base Scopus, após a inserção dos dois termos-chave e da aplicação dos filtros de busca (apenas artigos que contivessem os termos de interesse em seu resumo, título ou palavras-chave os termos-chave, até março de 2020), resultou em 784 publicações (Quadro 1).

Quadro 1: Dados blibliométricos obtidos a partir de consulta à base de dados Scopus

\begin{tabular}{|l|l|}
\hline \multicolumn{2}{|c|}{ Base de dados Scopus } \\
\hline Termos de busca & "concept maps” and “education” \\
\hline Campos de busca & Título, resumo e palavras-chave \\
\hline Total de trabalhos encontrados & 784 \\
\hline Autores & 2019 \\
\hline Fontes de publicação & 443 \\
\hline Instituições & 889 \\
\hline Países & 54 \\
\hline Áreas do conhecimento & 26 \\
\hline Tipos de publicação & Artigos \\
\hline
\end{tabular}

Fonte: elaborado pelas autoras

A partir da análise dos documentos, traçamos uma linha temporal das publicações, apresentada na Figura 2.

Figura 2: Linha temporal das publicações contendo os termos-chave

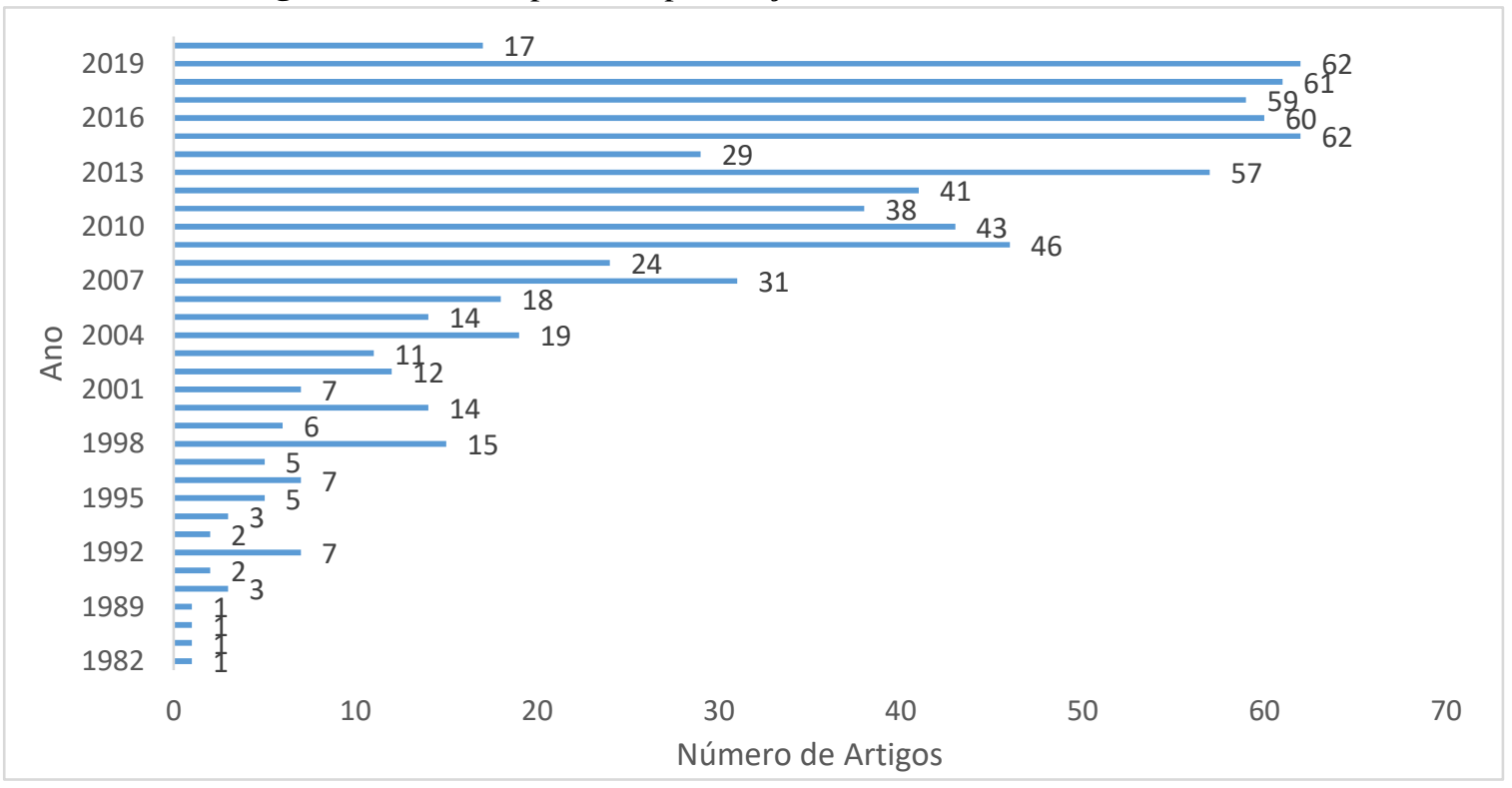

Fonte: elaborado pelas autoras

Desde o primeiro artigo, em 1982, a quantidade de publicações vem aumentando, apresentando os maiores valores entre 2015 e 2019, com uma média de produção de 61 
artigos nesse intervalo. Essas publicações estão distribuídas entre 26 áreas do conhecimento (Quadro 1). As dez áreas do conhecimento que mais publicaram artigos nos quais constam os termos-chave foram: Ciências Sociais (561), Ciência Computacional (102), Medicina (95), Engenharia (93), Enfermagem (91), Psicologia (47), Negócios, Gestão e Qualidade (43), Artes e Humanidades (32), Matemática (28) e Ciência Ambiental (27) ${ }^{4}$. Os valores inseridos dentro dos parênteses representam a quantidade de artigos publicados.

\section{1 Perfil dos periódicos}

Os dez periódicos com maior número de publicações de artigos nos quais constam os termos de interesse desta pesquisa estão dispostos no Quadro 2. Para avaliar o impacto dessas publicações, utilizou-se o Índice H. Inicialmente, esse indicador, proposto por Hirsch (2005), constituía um parâmetro avaliativo de um autor, relacionando seu número de publicações científicas e a quantidade de citações. Atualmente, além de avaliar pesquisadores, esse índice também é utilizado em relação a universidades e revistas científicas. Por exemplo, um índice H igual a 10 no período de três anos para um periódico significa que pelo menos dez de seus artigos receberam 10 citações nesse período (COLEPICOLO, 2016).

Quadro 2: Periódicos que mais publicaram artigos com os termos-chave em função do índice H.

\begin{tabular}{ccc}
\hline Periódico & Índice H & $\begin{array}{c}\text { Número de } \\
\text { Publicações }\end{array}$ \\
\hline Computers and Education & 14 & 19 \\
Medical Teacher & 13 & 15 \\
Journal of Research in Science Teaching & 10 & 12 \\
Journal of Chemical Education & 6 & 11 \\
Journal of Nursing Education & 7 & 10 \\
Knowledge Management and E-Learning & 4 & 10 \\
Nurse Education Today & 6 & 10 \\
Research in Science Education & 7 & 10 \\
International Journal of Continuing Engineering Education and & 2 & 9 \\
Life-Long Learning & & \\
\hline
\end{tabular}

Fonte: elaborado pelas autoras

As revistas científicas Computers and Education, Medical Teacher and Journal of Research in Science Teaching foram as que apresentaram o maior fator de impacto (índice H) e maior quantidade de publicações.

\footnotetext{
${ }^{4}$ Os valores inseridos entre parênteses representam a quantidade de publicações por área.
} 


\subsection{Publicação por instituição}

A Figura 3, a seguir, traz a representação gráfica das dez instituições que mais publicaram artigos nos quais constam os termos-chave. Os Estados Unidos lideram o ranking, com quatro universidades: University of California (15 artigos), Stanford University (10 artigos), Purdue University (9 artigos), Vanderbilt University (9 artigos). Em seguida, está o Reino Unido com a University of Surrey (13 artigos) e a King's College of London (9 artigos), seguido por Taiwan, representado pelas universidades National Taiwan Normal University e National University of Tainan, ambas com nove artigos cada. Empatado com Taiwan está o Brasil, também com nove artigos. A Austrália foi o país com o menor número de publicações: oito artigos pela Griffith University.

Figura 3: Instituições que mais publicaram artigos com os termos-chave

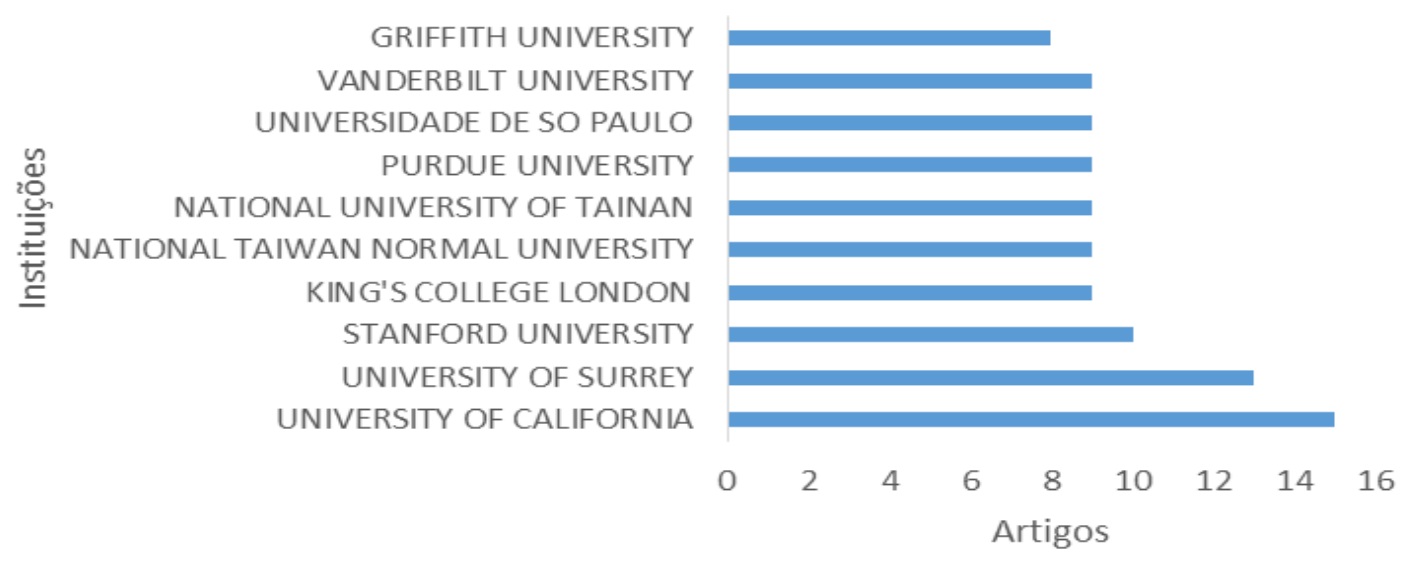

Fonte: elaborado pelas autoras.

\subsection{Publicação por autores}

A Figura 4 e o Quadro 3 ilustram a relação dos dez autores que mais produziram artigos científicos sobre o tema, bem como o índice $\mathrm{H}$ de cada um. 
Figura 4: Os dez autores que mais publicaram artigos com os termos-chave

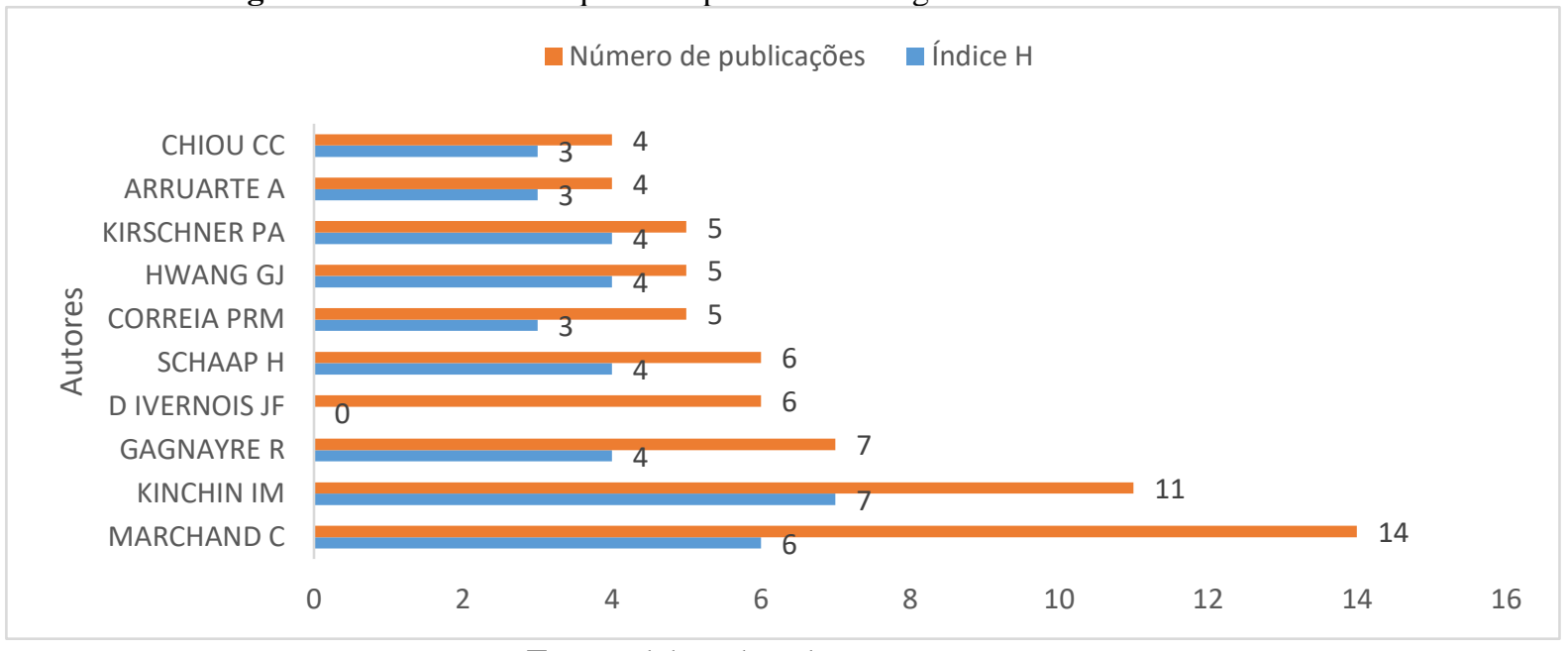

Fonte: elaborado pelas autoras

Quadro 3: Autores que mais publicaram artigos com os termos-chave, com suas respectivas filiações e índice $\mathrm{H}$

\begin{tabular}{|c|c|c|c|c|}
\hline Autor & Filiação & País & $\begin{array}{c}\text { Número de } \\
\text { artigos }\end{array}$ & $\begin{array}{c}\text { Índice } \\
\mathbf{H}\end{array}$ \\
\hline MARCHAND, C. & Paris University 13 & França & 14 & 6 \\
\hline KINCHIN, I. M. & Surrey University & Reino Unido & 11 & 7 \\
\hline GAGNAYRE, R. & Paris University 13 & França & 7 & 4 \\
\hline $\begin{array}{l}\text { DIVERNOIS, J. } \\
\text { F. }\end{array}$ & $\begin{array}{l}\text { Laboratoire de Éducation et } \\
\text { Pratique de Santé EA }\end{array}$ & França & 6 & 0 \\
\hline SCHAAP, H. & Radboud University Nijmegen & Holanda & 6 & 4 \\
\hline $\begin{array}{l}\text { CORREIA, P. R. } \\
\text { M. }\end{array}$ & Universidade de São Paulo & Brasil & 5 & 3 \\
\hline HWANG, G. J. & $\begin{array}{l}\text { National Taiwan University o } \\
\text { Science and Technology }\end{array}$ & Taiwan & 5 & 4 \\
\hline $\begin{array}{l}\text { KIRSCHNER, P. } \\
\text { A. }\end{array}$ & $\begin{array}{l}\text { Finland Open University of the } \\
\text { Netherlands }\end{array}$ & Holanda & 5 & 4 \\
\hline ARRUARTE, A. & Universidad del Pais Vasco & Espanha & 4 & 4 \\
\hline CHIOU, C. C. & $\begin{array}{l}\text { National Changhua University of } \\
\text { Education }\end{array}$ & Taiwan & 4 & 3 \\
\hline
\end{tabular}

Fonte: elaborado pelas autoras

Os resultados mostram que o pesquisador Paulo Rogério Miranda Correia, afiliado à Universidade de São Paulo, está na lista dos dez autores que publicam na área.

\subsection{Publicações mais citadas}

O Quadro 4 apresenta a relação dos dez artigos mais citados na base Scopus utilizando-se os termos-chave da pesquisa. Observa-se que somente um autor, Kinchin I. M., filiado à Surrey University, encontra-se tanto na lista dos autores que mais publicaram sobre o tema (Figura 4) quanto na lista de autores mais citados. Com isso, constata-se que os autores com elevado número de publicações podem não ser aqueles que produzem artigos de maior impacto e relevância na área de conhecimento em questão. Todas as 
publicações foram redigidas na língua inglesa, o que oferece maior visibilidade e impacto do que os artigos publicados em outras línguas.

Quadro 4: As dez publicações sobre o tema em função do número de citações

\begin{tabular}{cccc}
\hline Autores & Periódico & Citações & Citações/ano \\
\hline KNIGHT; WOOD, 2005 & Cell Biology Education & 378 & 23,6 \\
KARPICKE; BLUNT, 2011 & Science & 377 & 37,7 \\
KINCHIN; HAY; ADAMS, & Educational Research & 306 & 14,6 \\
2000 & Computers \& Education & 205 & 15,8 \\
CHEN; CHANG; WANG, & 2008 & 202 & 7,5 \\
$\begin{array}{c}\text { MARKHAM; MINTZES; } \\
\text { JONES, 1994 }\end{array}$ & $\begin{array}{c}\text { Journal of Research in } \\
\text { Science Teaching }\end{array}$ & Computers \& Education \\
HWANG; YANG; WANG, & $\begin{array}{c}\text { Co13 } \\
\text { TURNS; ATMAN; ADAMS, } \\
\text { 2000 }\end{array} \quad \begin{array}{c}\text { IEEE Transactions on } \\
\text { Education }\end{array}$ & 174 & 21,8 \\
NOVAK; CAÑAS, 2006 & $\begin{array}{c}\text { Information Visulization } \\
\text { Higher Education }\end{array}$ & 146 & 7,8 \\
ENTWISTLE et al., 2000 & $\begin{array}{c}\text { Research \& Development } \\
\text { Journal of American }\end{array}$ & 124 & 5,7 \\
WEST D. C., 2000 & Medical Association & 122 & 5,9 \\
\hline
\end{tabular}

Fonte: elaborado pelas autoras

O artigo mais citado, de autoria de Knight e Wood (2005), avaliou a aplicação de diferentes métodos de ensino a alunos de biologia do ensino superior a fim de averiguar o ganho de aprendizagem. Foram comparadas aulas meramente expositivas com outras que incluíam o uso de MCs e propiciavam maior interação e colaboração dos alunos. Os autores concluíram que cursos que privilegiam o engajamento interativo e o trabalho cooperativo entre os discentes leva a um aumento significativo da aprendizagem, proporcionando melhor entendimento conceitual, quando comparado ao método tradicional.

No segundo artigo mais citado, Karpicke e Blunt (2011) compararam a eficácia da prática de recuperação do conhecimento com o estudo elaborativo no ganho da aprendizagem de alunos do ensino superior. Para isso, os estudantes elaboraram MCs na presença e na ausência do material estudado. Segundo os autores, recuperação dos conteúdos é maior na aprendizagem significativa do que em estudos elaborativos, podendo ser aplicada como uma ferramenta eficaz para promover o aprendizado conceitual de Ciências.

O artigo mais citado em terceiro lugar, de Kinchin, Hay e Adams (2000) traz uma abordagem qualitativa para analisar os MCs produzidos por estudantes alunos. Os autores classificam três padrões de mapas (spoken, chain e net), associados a indicadores de compreensão, que podem auxiliar o professor em um ensino que produza uma 
aprendizagem mais eficaz, podendo ainda ser utilizado como base para estruturar grupos em ambientes colaborativos.

No trabalho mais citado em quarto lugar, Chen, Chang e Wang (2008) propõem a criação de um ambiente de aprendizagem onipresente, que possa ocorrer em qualquer hora e em qualquer lugar através da web e que possa ser utilizado a partir de qualquer dispositivo para melhorar a aquisição de conhecimentos por parte dos estudantes. Nesse contexto, a técnica de mapeamento foi aplicada à estrutura de conhecimento para revelar o status e a sequência de aprendizagem aos alunos.

Na quinta posição, Markham, Mintzes e Jones (1994) avaliaram mapas construídos por estudantes com diferentes níveis de conhecimento sobre o conteúdo de mamíferos, estudado em Biologia para explorar as diferenças na complexidade estrutural das bases de conhecimentos desses alunos. Os resultados mostraram que os mapas construídos por alunos mais avançados são estruturalmente mais complexos do que aqueles elaborados por alunos iniciantes. Os autores concluem que o MC fornece uma ferramenta teoricamente poderosa e psicometricamente sólida para avaliar a mudança conceitual em configurações experimentais e de sala de aula.

Em sexto lugar, a publicação de Hwang, Yang e Wang (2013) sugere a construção de um jogo educacional através de MCs para estimular o aprendizado. Os resultados mostraram que o uso do mapa conceitual em jogos melhora significativamente o desempenho dos alunos e diminui a carga cognitiva. Além disso, os alunos que aprenderam através dessa abordagem revelaram um grau significativamente maior de utilidade em relação aos que utilizaram a abordagem convencional de aprendizagem baseada em jogos.

Turn, Atman e Adams (2000) publicaram o sétimo artigo mais citado sobre o tema. Os autores apresentaram exemplos do uso de MCs para avaliação de nível de curso e de nível de programa para a área de engenharia e concluíram que essa ferramenta constitui uma forma inovadora de avaliar o aprendizado do aluno sobre os relacionamentos entre os conceitos.

Na oitava posição, Novak e Cañas (2006) descrevem os fundamentos teóricos do estudo de Novak que o levou ao desenvolvimento da ferramenta de MCs e suas aplicações. Em nono lugar mais citado, a publicação de Entwistle e colaboradores (2000) traz um estudo empírico para distinguir as crenças e concepções sobre o que é um bom ensino e explorar suas possíveis origens. Os dados foram obtidos a partir de professores em formação e os resultados contribuem para o pensamento atual sobre as concepções da 
docência no ensino superior. A técnica de mapeamento foi utilizada para sintetizar as descobertas.

Por último, temos o artigo de West et al., (2000), cujo objetivo foram avaliar: a) se a técnica de mapeamento refletia as diferenças e mudanças esperadas na estrutura conceitual de médicos residentes; b) se os MCs poderiam ser pontuados de forma confiável e; c) quão bem as pontuações dos mapas se relacionam com os resultados do exame padrão. Os autores reportam que o uso dos mapas como ferramenta avaliativa refletiu as diferenças e mudanças na estrutura conceitual dos médicos residentes.

\subsection{Distribuição da produção de periódicos}

A Figura 5 representa a distribuição da produção de periódicos em nível mundial. A intensidade da cor azul no mapa sinaliza relaciona-se positivamente à produção em cada país. A figura ainda traz a relação dos dez países que mais produziram cientificamente, estando os Estados Unidos em primeiro lugar com 533 publicações, enquanto o Brasil aparece em sétima posição com 60 artigos.

Figura 5: Distribuição da produção científica relacionada ao tema em quetão em nível mundial

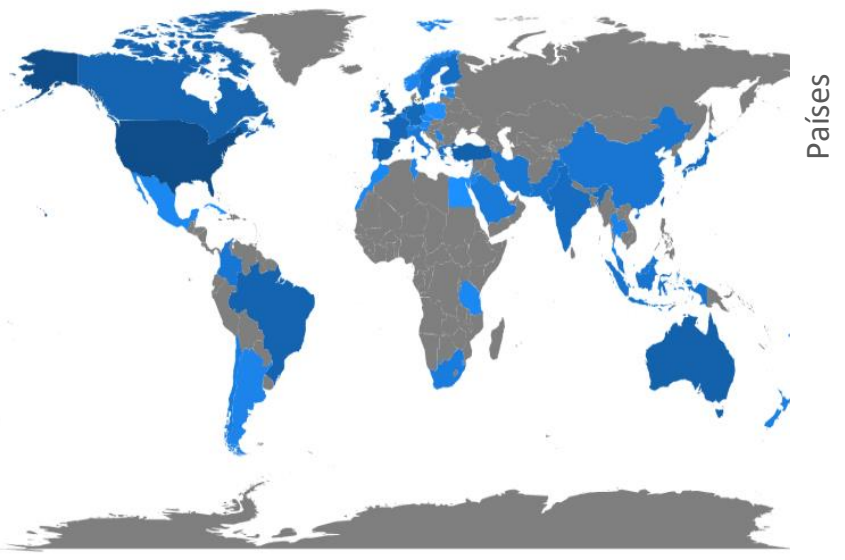

$$
\begin{array}{r|l}
\text { França } & 39 \\
\text { Espanha } & 54 \\
\text { Canadá } & 56 \\
\text { Brasil } & 60 \\
\text { Holanda } & 74 \\
\text { Turquia } & 79 \\
\text { Taiwan } & 79 \\
\text { Australia } & 84 \\
\text { Reino... } & 100 \\
\text { Estados... } & 533 \\
0 & 500 \quad 1000 \\
\text { Número de Publicações }
\end{array}
$$

Fonte: elaborado pelas autoras

\subsection{Mapeamento de palavras-chave}

A Figura 6 apresenta o mapeamento das palavras-chave mais utilizadas pelos autores. O tamanho da palavra está positivamente relacionado à frequência de sua citação, sendo esse número apresentado entre parênteses na discussão a seguir. 
Figura 6: Mapeamento das palavras-chave usadas pelos autores

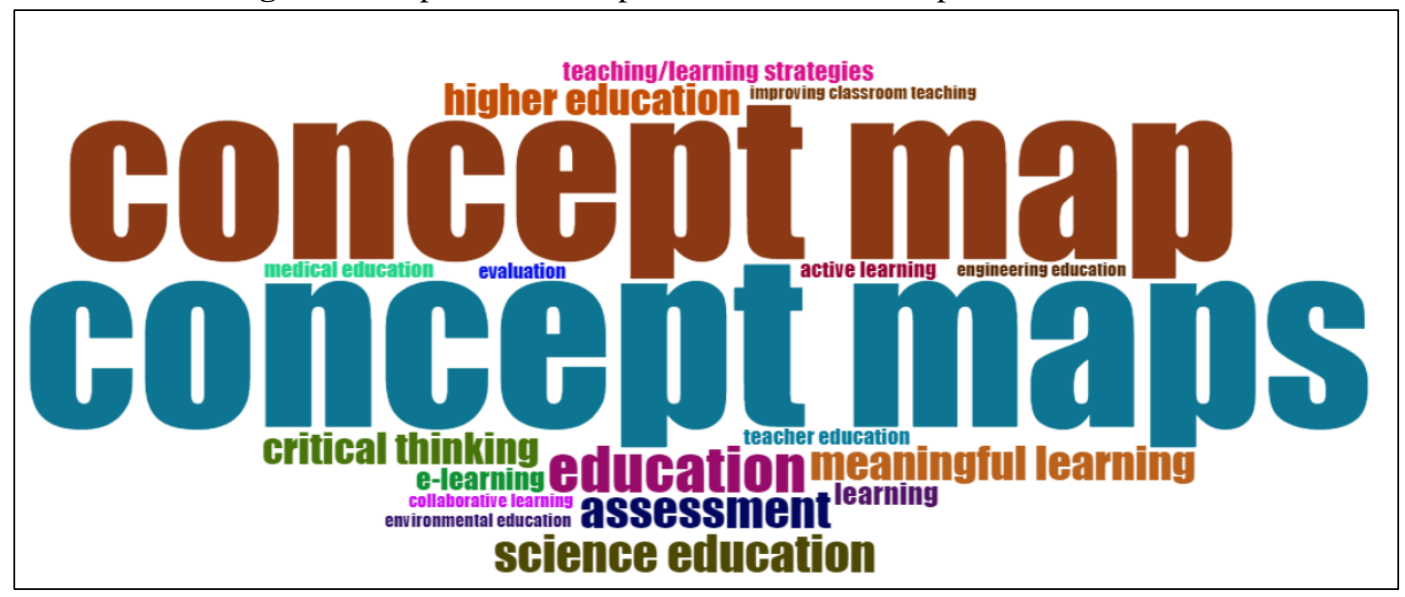

Fonte: elaborado pelas autoras

Como esperado devido à sua relação com o tema, as palavras-chave mais frequentes foram: mapas conceituais (116), mapa conceitual (110), mapeamento conceitual (106), educação (31), aprendizagem significativa (23) e pensamento crítico (21). Além disso, percebe-se uma associação com as palavras avaliação (25), educação científica (25) e ensino superior (21). ${ }^{5}$ Embora tenha-se utilizado apenas dois termoschave no mapeamento dos estudos para abranger o maior quantitativo de publicações, percebe-se que as pesquisas selecionadas caracterizam de forma satisfatória o uso de MCs no contexto educacional a partir dessa análise da frequência de palavras-chave.

\section{Considerações finais}

A sociedade contemporânea tem exigido uma nova forma de aprender, de ensinar e de se relacionar. Uma educação mecanizada, descontextualizada, acrítica, sem elos entres os atores envolvidos no processo de ensino-aprendizagem tende a dispensar muita energia e gerar poucos resultados. Com o intuito de reverter esse quadro, ferramentas que favorecem a aprendizagem significativa têm sido empregadas, como é o caso da TE dos MCs. Uma das razões pelas quais o uso dos MCs facilita a aprendizagem significativa é porque eles servem como suporte para ajudar a estruturar e organizar o conhecimento (NOVAK; CAÑAS, 2010).

A partir do estudo bibliométrico, realizado com os termos-chave, encontramos um cenário crescente de publicações, com 784 documentos, compreendidos entre o período de 1982 a março de 2020. Dentre essas publicações, 60 são provenientes de

\footnotetext{
5 Tradução das autoras.
} 
autores/instituições brasileiras e a área de estudo com maior número de publicações foi a de Ciências Sociais.

As instituições que mais publicaram sobre o tema encontram-se nos Estados Unidos e no Reino Unido. Os Estados Unidos também aparecem como o país com o maior de número de publicações, possivelmente devido ao fato de que a técnica de mapeamento digital foi idealizada nesse país por Joseph Novak, da Universidade de Cornell. No Brasil, o autor que mais publicou e teve artigo citados com os termos-chave foi Correia, da Universidade de São Paulo.

Através da análise dos dez artigos mais citados, constatou-se uma dinamicidade no uso da técnica de MCs no contexto educacional, nas mais diversas áreas e níveis de escolaridade, destacando-se como instrumento visando à organização, apresentação e revisão do conhecimento, como ferramenta de colaboração e de interação nas aulas e como recurso para avaliação da aprendizagem. Por fim, a busca pelas palavras-chave mais utilizadas pelos autores mostrou associações às expressões e termos aprendizagem significativa, educação científica, pensamento crítico, avaliação e ensino superior.

Muitas vezes confundidos com mapas mentais e fluxogramas, tem-se a ideia de que a construção dos MCs é um processo simples e trivial. Entretanto, trata-se de recursos que podem provocar alterações significativas na maneira de ensinar, aprender, avaliar e colaborar. A importância da técnica também pode ser observada pelo fato de que mesmo após 50 anos da sua apresentação à comunidade, por Joseph Novak, observa-se uma produção científica crescente envolvendo seu uso direto ou sua combinação com outras estratégias de ensino, visando promover a aprendizagem com significado.

\section{Referências}

ARAÚJO, C. A. A. Bibliometria: evolução histórica e questões atuais. Em Questão, Porto Alegre, RS, v. 12, n. 1, p. 11-32, jan./jun. 2006.

ARIA, M.; CUCCURULLO, C. Bibliometrix: an R-tool for comprehensive science mapping analysis, Journal of Informetrics, Amsterdam, v. 11, n. 4, p. 959-975, nov. 2017.

AUSUBEL, D. P. Aquisição e retenção de conhecimentos: uma perspectiva cognitiva. Tradução de Teopisto, L. Revisão científica, Teodoro, V.D. Lisboa. Lisboa: Plátano Edições Técnicas, 2003, 243 p.

BRASIL. Secretaria Nacional de Educação Média e Tecnológica. Conversas com o Professor sobre tecnologias educacionais - Tema 1: Tecnologias educacionais no ensino médio: para quê? Brasília. DF, 2004. Disponível em:

http://portal.mec.gov.br/seb/arquivos/pdf/conversas01.pdf. Acesso em: 15 abr. 2020. 
CAÑAS, A. J. et al. (org.). Concept maps: theory, methodology, technology.

INTERNATIONAL CONFERENCE ON CONCEPT MAPPING, 1., 2004, Pamplona.

Proceedings... Pamplona, Spain: Universidad Pública de Navarra, 2004. p.125-133.

CHEN, G. D.; CHANG, C. K.; WANG, C. Y. Ubiquitous learning website: Scaffold learners by mobile devices with information-aware techniques. Computers \& education, Amsterdam, v. 50, n. 1, p. 77-90, jan. 2008.

COLEPICOLO, E. Como obter o índice H de um periódico pela base Scopus. Portal de Periódicos UFSCAR, 20 set. 2016. Disponível em:

http://www.periodicos.ufscar.br/noticias/como-obter-o-indice-h-de-um-periodico-pela-basescopus. Acesso em: 16 abr. 2020.

CORREIA, P. R. M.; SILVA, A. C.; ROMANO JR., J. G. Mapas conceituais como ferramenta de avaliação na sala de aula. Revista Brasileira de Ensino de Física, São Paulo, v. 32, n. 4, p.4402-1 - 4402-8, 2010.

CORREIA, P. R. M. The use of concept maps for knowledge management: from lassrooms to research labs. Analytical and Bioanalytical Chemistry, Heidelberg, v. 402, n. 6, p. 1979-1986, fev. 2012.

CORREIA, P. R. M. et al. Nova abordagem para identificar conexões disciplinares usando mapas conceituais. Ciências \&Educação, Bauru, v. 20, n. 2, p. 467-479, 2014.

CORREIA, P. et al. Por que vale a pena usar mapas conceituais no Ensino Superior? Revista De Graduação USP, São Paulo, v. 1, n. 1, p. 41-51, jul. 2016.

CUNHA, C. A. C.; DE PAULA, M. V. G; SUANNO, J. H. Mapa conceitual: da teoria de Ausubel à transdisciplinaridade. In: CONGRESSO DE EDUCAÇÃO, 12, 2015, Curitiba. PUCPR: EDUCERE, 2015. p. 5465-5480.

ENTWISTLE, N. et al. Conceptions and beliefs about "good teaching": An integration of contrasting research areas. Higher Education Research \& Development, London, v. 19, n. 1, p. 5-26, 2000.

HIRSCH, J. E. An index to quantify an individual's scientific research output. Proceedings of the National Academy of Sciences, v. 102, n. 46, p. 16569-16572, 2005.

HWANG, G. J.; YANG, L. H.; WANG, S. Y. A concept map-embedded educational computer game for improving students' learning performance in natural science courses. Computers \& Education, Amsterdam, v. 69, p. 121-130, nov. 2013.

KARPICKE, J. D.; BLUNT, J. R. Retrieval practice produces more learning than elaborative studying with concept mapping. Science, Washington, v. 331, n. 6018, p. 772-775, feb. 2011.

KINCHIN, I. M.; HAY, D. B.; ADAMS, A. How a qualitative approach to concept map analysis can be used to aid learning by illustrating patterns of conceptual development. Educational research, London, v. 42, n. 1, p. 43-57, 2000.

KNIGHT, J. K.; WOOD, W. B. Teaching more by lecturing less. Cell biology education, Rockville, v. 4, n. 4, p. 298-310, 2005.

MARKHAM, K. M.; MINTZES, J. J.; JONES, M. G. The concept map as a research and evaluation tool: Further evidence of validity. Journal of research in science teaching, New Jersey, v. 31, n. 1, p. 91-101, jan. 1994. 
MOREIRA, M. A. Teorias de aprendizagem. São Paulo: EPU, 1999.

MOREIRA, M. A. Mapas conceituais e aprendizagem significativa. São Paulo: Centauro, 2010.

MOREIRA, M. A. Aprendizagem significativa em mapas conceituais. Textos de apoio ao professor de Física. Porto Alegre, v. 24, n. 6, p. 1-49, 2013.

MOUSINHO, S. H., A utilização dos Mapas Conceituais para a construção dos conceitos no processo de aprendizagem. Revista EaD \& Tecnologias Digitais na Educação, Dourados, v. 7, n. 9 , p. $40-51,2019$.

NOVAK, J. D.; CAÑAS, A. J. The origins of the concept mapping tool and the continuing evolution of the tool. Information visualization, New York, v. 5, n. 3, p. 175-184, sep. 2006.

NOVAK, J. D.; CAÑAS, A. J. A teoria subjacente aos mapas conceituais e como elaborá-los e usá-los. Práxis Educativa, Ponto Grossa, v. 5, n. 1, p. 9-29, jul. 2010.

OKUBO, Y. Bibliometric Indicators and analysis of research systems: methods and examples. In: STI Working Papers, 1997, Paris: OECD, 1997, 71 p.

TAVARES, L. C.; MÜLLER, R. C. S.; FERNANDES, A. C. O uso de mapas conceituais como ferramenta metacognitiva no ensino de Química. Amazônia: Revista de Educação em Ciências e Matemáticas, Belém, v. 14, n. 29, p. 63-78, jan./jun. 2018.

TURNS, J.; ATMAN, C. J.; ADAMS, R. Concept maps for engineering education: A cognitively motivated tool supporting varied assessment functions. IEEE Transactions on Education, New Jersey, v. 43, n. 2, p. 164-173, may. 2000.

WEST, D. C. et al. Critical thinking in graduate medical education: a role for concept mapping assessment? Jama, Chicago, v. 284, n. 9, p. 1105-1110, sep. 2000.

Recebido em: 17 de janeiro de 2021.

Aceito em: 04 de março de 2021. 